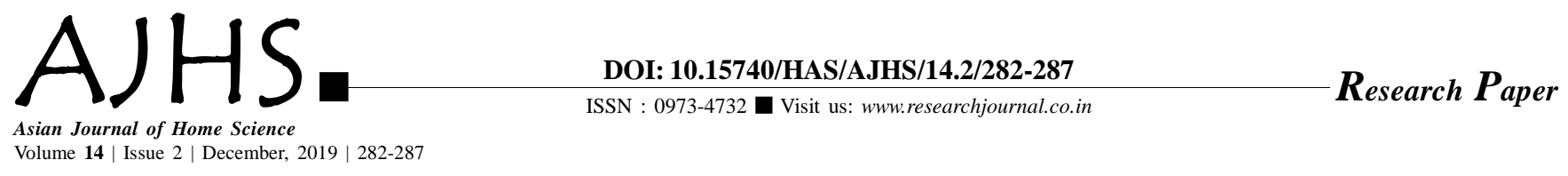

\title{
Life- style and physical- activity pattern of school going adolescent girls
}

\author{
Rakhee Katiyar and Gurmeet Kaur
}

See end of the paper for authors' affiliations Rakhee Katiyar

Department of Home Science, C.S.J.M. University, Kanpur (U.P.) India

Email : ashishkanaujia@

yahoo.com

Received: 02.05.2019; Revised: 05.10.2019; Accepted: 19.10.2019

ABSTRACT : The present study was conducted in Kanpur (U.P.) among 400 school going adolescent girls (13-19 years) for finding out their life style and physical activity pattern. From the investigation conducted it was observed that during their free time 42.6 per cent of girls watched television or laptop; 32.3 per cent slept for 7-8 hours in a day. To use the conveyance 32.7 per cent went to school by cycle and only 27.7 per cent participated in school sports or games. In house hold activity there was no involvement of 40.4 per cent girls. It was observed that 28.5 per cent purchased snacks form the school canteen for 2-3 times in a week; 34 per cent consumed full cream buffalo milk; 36 per cent used tap water and 46.5 per cent girls purchased food items from the market to fulfil their desire for particular taste. From the results of the study it can be concluded that the lifestyle and physical activity pattern of adolescent girls were greatly affected by the changes in their environment and forcing them to lead a unhealthy life. To overcome their problem, family, peer group and school together should plan and make needful efforts.

KEY WORDS: Adolescent, Lifestyle, Physical activity

- HOW TO CITE THIS PAPER : Katiyar, Rakhee and Kaur, Gurmeet (2019). Life- style and physicalactivity pattern of school going adolescent girls. Asian J. Home Sci., 14 (2) : 282-287, DOI: 10.15740/HAS/ AJHS/14.2/282-287. Copyright@ 2019: Hind Agri-Horticultural Society. 